\title{
Complex interactions between spatial pattern of resident species and invasiveness of newly arriving species affect invasibility
}

\author{
Aurélie Thébault $\cdot$ Peter Stoll $•$ Alexandre Buttler
}

Received: 25 August 2011 / Accepted: 18 May 2012 / Published online: 12 July 2012

(C) Springer-Verlag 2012

\begin{abstract}
Understanding the factors that affect establishment success of new species in established communities requires the study of both the ability of new species to establish and community resistance. Spatial pattern of species within a community can affect plant performance by changing the outcome of inter-specific competition, and consequently community invasibility. We studied the effects of spatial pattern of resident plant communities on fitness of genotypes from the native and introduced ranges of two worldwide invasive species, Centaurea stoebe and Senecio inaequidens, during their establishment stage. We experimentally established artificial plant mixtures with 4 or 8 resident species in intra-specifically aggregated or ran-
\end{abstract}

Communicated by Bryan Foster.

A. Thébault $(\bowtie) \cdot$ A. Buttler

Laboratory of Ecological Systems, School of Architecture,

Civil and Environmental engineering (ENAC),

Ecole Polytechnique Fédérale de Lausanne (EPFL),

Station 2, 1015 Lausanne, Switzerland

e-mail: aurelie.thebault@epfl.ch

A. Thébault · A. Buttler

WSL Swiss Federal Research Institute, Site Lausanne,

Station 2, 1015 Lausanne, Switzerland

P. Stoll

Department of Environmental Sciences, Section of Conservation Biology, University of Basel, St. Johanns-Vorstadt 10, 4056 Basel, Switzerland

P. Stoll

Institute of Plant Sciences, University of Bern, Altenbergrain 21, 3013 Bern, Switzerland

\section{A. Buttler}

Laboratoire de Chrono-Environnement, UMR CNRS 6249,

Université de Franche-Comté, 25030 Besançon, France dom spatial patterns, and added seedlings of genotypes from the native and introduced ranges of the two target species. Early growth of both $S$. inaequidens and $C$. stoebe was higher in aggregated than randomly assembled mixtures. However, a species-specific interaction between invasiveness and invasibility highlighted more complex patterns. Genotypes from native and introduced ranges of $S$. inaequidens showed the same responses to spatial pattern. By contrast, genotypes from the introduced range of $C$. stoebe did not respond to spatial pattern whereas native ones did. Based on phenotypic plasticity, we argue that the two target species adopted different strategies to deal with the spatial pattern of the resident plant community. We show that effects of spatial pattern of the resident community on the fitness of establishing species may depend on the diversity of the recipient community. Our results highlight the need to consider the interaction between invasiveness and invasibility in order to increase our understanding of invasion success.

Keywords Establishment success - Invasive species · Genotype $\cdot$ Phenotypic plasticity $\cdot$ Spatial aggregation

\section{Introduction}

Invasive exotic species are a threat to natural and managed ecosystems (Prieur-Richard and Lavorel 2000), because they can displace native species (Walker and Vitousek 1991; Vitousek et al. 1997; Levine et al. 2003; Reinhart et al. 2006), modify rates of ecosystem processes (Vitousek et al. 1997; Gordon 1998; Mack et al. 2001; Ehrenfeld 2003), and cause substantial losses to plant and animal agricultural production (Pimentel et al. 2000). Invasion success is the consequence of the ability of an exotic species to 
invade (invasiveness) and the lack of resistance of the recipient community (invasibility), which may be affected by propagule pressure (Simberloff 2009). So far, invasiveness and invasibility have rarely been studied together, despite growing evidence that their combined study is needed to fully understand invasion success (Hierro et al. 2005), since this depends on the niche of the invader matching the opportunities of the novel environment (Bazzaz 1986; Shea and Chesson 2002). It is therefore necessary to simultaneously consider both aspects to advance understanding of invasion processes.

The spatial pattern of plant communities has been demonstrated to affect species coexistence within communities by changing the outcome of inter-specific competition (Stoll and Prati 2001; Monzeglio and Stoll 2005; De Boeck et al. 2006; Mokany et al. 2008; Lamosova et al. 2010). As spatial intra-specific aggregation increases, strong competitors suffer from intra-specific competition, while weak competitors benefit by being segregated from stronger competitors (Stoll and Prati 2001). By reducing the importance of inter-specific competition, spatial aggregation can lead to a decrease in resource uptake and complementarity, which may increase the number of coexisting species (De Boeck et al. 2006; Mokany et al. 2008), and, consequently, affect invasibility (De Boeck et al. 2006). To our knowledge, the effect of spatial pattern of resident plant communities on its resistance to invasion has never been studied.

In most experiments on intra-specific aggregation, it has been assumed that only the density of different plant species varies in space and that the environment is otherwise homogeneous (Damgaard 2010). Since plant community composition and diversity may influence biotic interactions within communities, the effect of intra-specific aggregation could be mediated by community composition. In a microcosm experiment, the effect of spatial pattern on community productivity and complementarity has been shown to be mediated by community diversity (Lamosova et al. 2010). These findings imply that impacts of intra-specific aggregation on community resistance to invasion may depend on community composition.

The exotic species has to match community opportunities at each stage of the invasion process for a successful invasion (reviewed in Catford et al. 2009). This can be influenced by ecological processes, according to which invasion success is the consequence of extrinsic changes in the new environment that favor the invading species, without any intrinsic change of the invasive species (Callaway and Aschehoug 2000; Mack et al. 2000; Maron and Vila 2001; Keane and Crawley 2002; Hierro et al. 2005; Eppinga et al. 2006). Comparing the performances of genotypes from the introduced range of a species with those of its own native range, under the same growth conditions, provides an indication of which changes in the environment enable exotics to dominate recipient communities (Hierro et al. 2005; Dlugosch and Parker 2008).

In this study, we tested the effect of intra-specific aggregation on the early establishment success of two invasive species, namely the native and introduced genotypes of two worldwide invasive species, Senecio inaequidens and Centaurea stoebe. Specifically, we tested whether spatial pattern of the resident plant community differentially affected the performances of native and introduced genotypes of the two species during early stages of establishment. These two species: (1) belong to the same family (Asteraceae); (2) occupy similar ecological niches in their native range; and (3) tend to invade similar habitats in their introduced range. However, previous studies have shown that they have two different invasion mechanisms: Senecio inaequidens relies on an increased propagule pressure to invade (Thébault et al. 2011), whereas $C$. stoebe can induce changes in the soil bacterial community to succeed (Thébault et al. 2010). We experimentally established two types of artificial mixtures of intra-specifically aggregated and randomly dispersed resident plant species. One type of mixtures was composed of 4 resident species and the second of 8 resident species (hereafter called 4-species and 8-species mixtures, respectively), to which we added seedlings of native and introduced genotypes of the two invasive species. We hypothesized that: (1) since intra-specific aggregation is known to lower competitive potential of strong competitors and inter-specific competition, establishment success should be higher in aggregated compared to randomly dispersed species assemblage, but this may be mediated by (2) community composition and/or (3) the genotype's range.

\section{Materials and methods}

Invasive and resident species

Centaurea stoebe L. is a perennial tap-rooted forb with a rosette of basal leaves and relatively thick flowering stems (Hook et al. 2004; Treier et al. 2009). Native from western Asia to western Europe, Centaurea stoebe was introduced in the Pacific Northwest of the United States in the late 1800s (Watson and Renney 1974) and expanded rapidly throughout north-western America and western Canada, where it is now widespread in rangelands, pastures, and on roadsides (Skinner et al. 2000; Duncan 2001). Introduced genotypes are known to induce changes in soil bacterial communities, which may explain their invasion success (Thébault et al. 2010). Seeds of $C$. stoebe were collected during summer 2005 throughout its native range in Europe as well as in Montana and Oregon, USA, in its introduced range (Broennimann et al. 2007; Treier et al. 2009). In all, 15 populations from 97 available populations were ran- 
domly chosen for this study: 9 from native tetraploid populations and 6 from introduced populations known to be only tetraploids.

Senecio inaequidens D.C. is an erect perennial dwarf shrub native from South Africa and Lesotho. Originally found in grasslands from 1,400 to $2,800 \mathrm{~m}$ a.s.l., it is now common in South Africa. It was accidentally introduced to Europe at the end of 1880s (Bornkamm 2002) where it is now widespread, even at lower altitudes. It is also found in Australia and South America (Ernst 1998; Lafuma et al. 2003). According to a recent study, S. inaequidens is thought to successfully invade new areas through high propagule pressure (Thébault et al. 2011). Seeds of S. inaequidens (mostly provided by Dr. Daniel Prati, University of Bern) were collected in western Europe, South Africa and Lesotho (Lafuma et al. 2003). Additional seeds were collected from two populations in Switzerland. Of 89 available populations, 23 were randomly chosen: 14 native tetraploids and 9 introduced tetraploids.

Eight species commonly found in European grasslands were selected to build artificial communities. Seeds were provided by a local supplier (FENACO, Yverdon-lesBains, Switzerland). These species were chosen so as to belong to 3 functional groups: grasses (Arrhenaterum elatius, Agrostis capillaris, Bromus erectus, and Lolium perenne), legumes (Lotus corniculatus and Trifolium repens) and forbs (Achillea millefolium and Sanguisorba minor). To prevent the possible lack of germination of the resident species, a ninth species (the grass Festuca pratensis) was sown at the same time. After 10 days, $S$. minor did not have enough seedlings to be transplanted in the microcosms, leading to its replacement by $F$. pratensis. In the following sections, invasive species will be called target species, whatever the genotype's range considered, while species of the community will be addressed as resident species.

\section{Community assemblage—experimental setup}

On April 2008, seeds of the resident species composing the community were sown in peat seedbed cubes of $3.0 \times 3.5 \times 4 \mathrm{~cm}$. Seeds of target species (genotypes from the native and introduced ranges) were sown 2 weeks later in the same manner. All seeds were put in a dark germination chamber for 10 days before being assembled in a greenhouse. The 4-species mixtures were composed of A. elatius (A), L. perenne (B), $F$. pratensis $(\mathrm{C})$, and $T$. repens (D). The 8-species mixtures were composed of the four previous species (A, B, C, and D) in addition to B. erectus $(\mathrm{E})$, A. capillaris $(\mathrm{F})$, A. millefolium $(\mathrm{G})$, and L. corniculatus $(\mathrm{H})$. Thus, due to lack of germination of $S$. minor and its replacement by $F$. pratensis, the two mixture types vary in terms of composition and diversity. The mixtures were assembled 1 month after seed sowing, at the beginning of
May 2008, in boxes of $60 \times 60 \times 30 \mathrm{~cm}$ (hereafter called "plots"). All seedbed cubes were placed on a homogeneous substrate made of sand (67\%) and compost (33\%).

Spatial pattern (random vs. aggregated) and mixture types (4-species mixture vs. 8-species mixture) varied at the plot level, target species (S. inaequidens vs. C. stoebe) at the subplot level, and genotype's range (native vs. introduced) at the sub-subplot level, resulting in a randomized split-split plot design. All combinations of spatial patterns and mixture types were randomly assigned to plots and each treatment was replicated 4 times yielding 16 plots arranged in four blocks (Fig. 1a). The main plots of $60 \times 60 \mathrm{~cm}$ were subdivided into 2 subplots of $30 \times 60$ $\mathrm{cm}$, each one containing one of the target species. Each subplot was further subdivided into 2 sub-subplots of $30 \times 30 \mathrm{~cm}$ containing 8 experimental units. While one sub-subplot contained genotypes from the native range of the target species, the other one contained genotypes from the introduced range of the same target species (Fig. 1b). An experimental unit was defined as one individual of a range (genotype from the native range vs. genotypes from the introduced range) of one target species (C. stoebe vs. $S$. inaequidens) for a combination of a spatial pattern and a mixture type (Fig. 1b). Within each experimental unit, the individual target species was surrounded by 8 seedlings of resident species. In the random pattern, target species were growing in the middle of a mixture of resident species, simulating a seed growing in a mosaic of resident species. By contrast, in the spatially aggregated pattern, the 8 surrounding seedlings belonged to the same resident species, simulating a seed arriving in a patch of one resident species or a monoculture (Fig. 1c).

\section{Measurements}

Survival was measured 15 days after the mixture assemblage to test for effects of the experimental setup on establishment. A harvest of target species was done 1.5 months after mixture assemblage. Surviving targets were counted and aboveground parts of surviving plants were harvested, dried at $60{ }^{\circ} \mathrm{C}$ during 3 days, and weighed for measurement of standing biomass. A second harvest of resprouting plants was done 4 months after mixture assemblage. As for the first harvest, survival of resprouted plants was measured and aboveground biomass was dried at $60{ }^{\circ} \mathrm{C}$ during 3 days before being weighed. During the experiment, flowering was recorded and analyzed as a binary response (flowering/ non-flowering) for individuals during the experiment. Capitula of target species (capitulum production) were counted weekly and cut since we wanted to prevent seed dispersal for safety reasons. At each harvest, resident plant species were mown, sorted to the functional group level, dried at $60^{\circ} \mathrm{C}$ for 3 days and weighed. 
Fig. 1 a Diagrammatic representation of the design of the experiment: a split plot design, with sub-subplot nested into subplot nested into plot arranged in block, each sub-subplot containing 8 experimental units. Main effects varied at the plot level, so each block had one replicate of each mixture type-spatial pattern combination. b Diagram of the design at the plot level: each subplot had one of two target species (C. stoebe or $S$. inaequidens) and was divided into sub-subplots planted with seedlings from the native range or introduced range of the target species. c Spatial pattern (aggregated vs. random) and mixture type (4-species or 8species mixture) varied at the plot level. $A-H$ represent resident species (A, A. elatius; $\mathrm{B}, L$. perenne; C, F pratensis; D, T. repens; E, B. erectus; $\mathrm{F}$, A. capillaris; $\mathrm{G}$, A. millefolium and $\mathrm{H}$, L. corniculatus).

$\mathrm{Cn}, \mathrm{Ci}, \mathrm{Sn}$, and $\mathrm{Si}$ are the target species: respectively Centaurea stoebe from the native and introduced ranges and Senecio inaequidens from the native and introduced ranges (a)

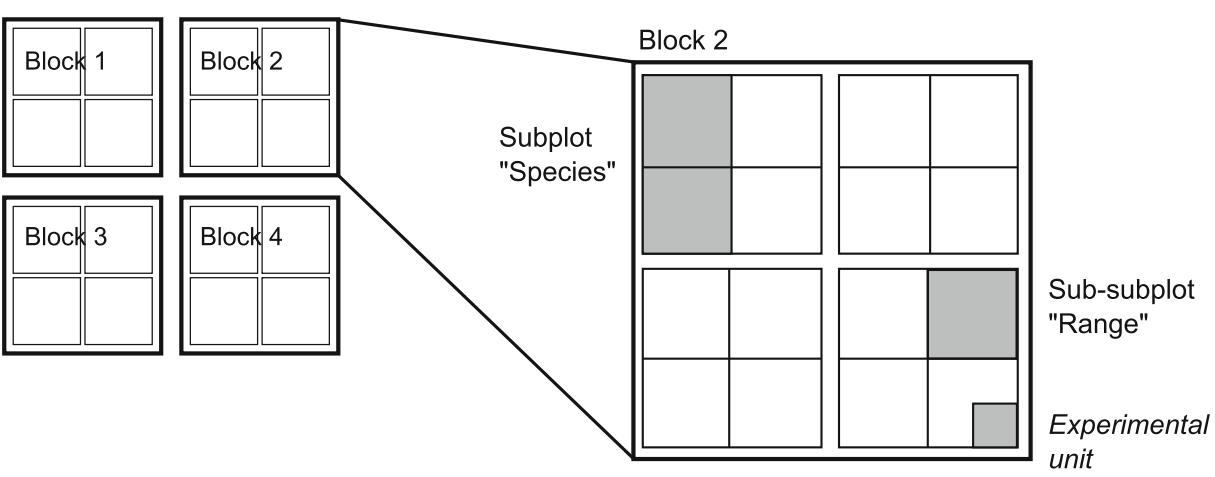

(b) S. inaequidens (S) C. stoebe (C)

\begin{tabular}{|c|c|c|c|c|c|c|c|c|c|c|c|c|c|c|c|c|}
\hline & $B$ & & & $\mathrm{D}[\mathrm{L}$ & & $\mathrm{AB}$ & B & B & & & & \begin{tabular}{l|l}
$\mathrm{D}$ & $\mathrm{C}$
\end{tabular} & \begin{tabular}{l|l}
$c$ & $A$
\end{tabular} & & & \multirow{9}{*}{$\begin{array}{l}\text { Introduced } \\
\text { range (i) }\end{array}$} \\
\hline $\begin{array}{ll} \\
\end{array}$ & $S n$ & $\begin{array}{ll} \\
\end{array}$ & \begin{tabular}{l|l|}
$A$ \\
\end{tabular} & & $\begin{array}{l}40 \\
\end{array}$ & & C & $\mathrm{A}$ & $\mathrm{Ci}$ & 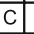 & $\begin{array}{llc}\text { C } \\
\end{array}$ & \begin{tabular}{c|c|} 
& $A$
\end{tabular} & \begin{tabular}{l|l}
$A$ & $D$ \\
\end{tabular} & & B & \\
\hline D & \begin{tabular}{|c|} 
\\
\end{tabular} & \begin{tabular}{|l|} 
D \\
\end{tabular} & & & & $\mathrm{C}$ & $\bar{D}$ & $\mathrm{D}$ & $\begin{array}{lll}C^{\prime} \\
\end{array}$ & \begin{tabular}{|l|} 
D \\
\end{tabular} & & & $\begin{array}{lll}A C \\
\end{array}$ & & & \\
\hline $\mathrm{A}$ & \begin{tabular}{l|l}
$c$ \\
\end{tabular} & D & & & & 30 & $\bar{A}$ & A & \begin{tabular}{l|l}
$c$ & 1 \\
\end{tabular} & D & & & B & & & \\
\hline$B$ & $S n$ & $\mathrm{D}$ & & & $\bar{B}$ & \begin{tabular}{l|l}
3 \\
\end{tabular} & D & $\mathrm{B}$ & $\mathrm{Ci}$ & $\begin{array}{ll}\mathrm{C} \\
\text {. }\end{array}$ & & & $B$ & & D & \\
\hline $\mathrm{A}$ & $B$ & $\mathrm{C}$ & & & C & $D$ & $\mathrm{~A}$ & $B$ & $\mathrm{D}$ & $\mathrm{A}$ & & & $\mathrm{C}$ & \begin{tabular}{|l|l|} 
\\
\end{tabular} & $\bar{A}$ & \\
\hline$c$ & \begin{tabular}{|l|}
$\mathrm{A}$ \\
\end{tabular} & A & & B & $\begin{array}{c}C B \\
\end{array}$ & \begin{tabular}{|l|l}
3 & $\mathrm{~A}$ \\
\end{tabular} & C & $\begin{array}{ll}c \\
\end{array}$ & $\mathrm{~A}$ & $\mathrm{~A}$ & & \begin{tabular}{l|l}
$B$ & $B$ \\
\end{tabular} & \begin{tabular}{|l|l}
3 & $C$ \\
\end{tabular} & A & $\bar{c}$ & \\
\hline $\mathrm{D}$ & Sn & B & & Sn & $\begin{array}{ll}3 & 0 \\
\end{array}$ & $S t$ & A & $\mathrm{D}$ & $\mathrm{Ci}$ & $c$ & & $\mathrm{Ci}$ & \begin{tabular}{|l|l} 
\\
\end{tabular} & $\mathrm{Ci}$ & & \\
\hline$B$ & $c$ & $\mathrm{D}$ & $\mathrm{A} \mid$ & \begin{tabular}{c|c}
$c$ & 5
\end{tabular} & $D$ B & \begin{tabular}{l|l}
3 & $D$ \\
\end{tabular} & $\mathrm{D}$ & $\mathrm{D}$ & B & $\mathrm{B}$ & A & \begin{tabular}{c|c}
$c 10$ \\
\end{tabular} & \begin{tabular}{c|c}
$C$ & $B$ \\
\end{tabular} & \begin{tabular}{|c|}
$B$ \\
\end{tabular} & $\mathrm{D}$ & \\
\hline $\mathrm{A}$ & $\mathrm{D}$ & \begin{tabular}{l|l} 
B \\
\end{tabular} & $\mathrm{A}$ & $\begin{array}{lll}B & C\end{array}$ & \begin{tabular}{c|c}
$C A$ \\
\end{tabular} & $\mathrm{~A} \mid \mathrm{B}$ & $D$ & $\mathrm{~A}$ & $c$ & \begin{tabular}{|l|} 
\\
\end{tabular} & $c 1$ & $\mathrm{DI}^{\circ}$ & $\overline{\mathrm{A}}$ & $c \mid$ & $\bar{B}$ & \multirow{6}{*}{$\begin{array}{l}\text { Native } \\
\text { range }(n)\end{array}$} \\
\hline $\mathrm{D}$ & $S i$ & $\mathrm{~A}$ & $\mathrm{~A}$ & Si $\mathrm{L}$ & 50 & $s$ & C & \begin{tabular}{|l|} 
C \\
\end{tabular} & $C_{n}$ & $\mathrm{~A}$ & $\begin{array}{llc}B \\
\end{array}$ & Cn & \begin{tabular}{c|c}
$c$ & $C$ \\
\end{tabular} & $c_{n}$ & $B$ & \\
\hline B & $\begin{array}{ll}\text { C } \\
\end{array}$ & \begin{tabular}{c|} 
c \\
\end{tabular} & \begin{tabular}{c|}
$c$ \\
\end{tabular} & \begin{tabular}{l|l}
$B$ & $L$
\end{tabular} & $\mathrm{DA}$ & $\mathrm{A}$ & D & $\mathrm{D}$ & $\begin{array}{ll} \\
\end{array}$ & $\mathrm{D}$ & & & \begin{tabular}{|l|l}
3 & $A$ \\
\end{tabular} & & $D$ & \\
\hline$c$ & $c$ & $B$ & & & 10 & 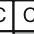 & $\mathrm{D}$ & $\mathrm{A}$ & $c$ & $\mathrm{D}$ & & & $\mathrm{A}$ & \begin{tabular}{ll|l} 
\\
\end{tabular} & $B$ & \\
\hline D & $S i$ & $\mathrm{D}$ & & & B & $\begin{array}{l}3 \\
S\end{array}$ & $\mathrm{~A}$ & $\mathrm{~B}$ & $\mathrm{Cn}$ & $\mathrm{D}$ & & & $D$ & $c_{n}$ & $\bar{D}$ & \\
\hline A & \begin{tabular}{|l|} 
\\
\end{tabular} & $\begin{array}{l} \\
\end{array}$ & & & D & $5 \mathrm{~A}$ & B & $B$ & $\mathrm{~A}$ & $\begin{array}{c}\mathrm{c} \\
\end{array}$ & & & $B$ & \begin{tabular}{lc|} 
C \\
\end{tabular} & A & \\
\hline $\mathrm{A}$ & $B$ & \begin{tabular}{c|} 
\\
\end{tabular} & $\mathrm{B}$ & $\begin{array}{ll}\mathrm{D} \\
\end{array}$ & $\begin{array}{l}4 \\
\end{array}$ & $\mathrm{~A}$ & C & $\mathrm{D}$ & $\begin{array}{ll} \\
\end{array}$ & \begin{tabular}{l|l} 
B \\
\end{tabular} & & \begin{tabular}{l|c}
$B$ & $C$ \\
\end{tabular} & $\mathrm{C} / \mathrm{C}$ & D & $\bar{A}$ & \multirow{3}{*}{$\begin{array}{l}\text { Experimental } \\
\text { unit }\end{array}$} \\
\hline $\mathrm{D}$ & Si & B & & Si & \begin{tabular}{|l|l}
3 & $B$ \\
\end{tabular} & \begin{tabular}{l|l}
3 & 5 \\
\end{tabular} & $\mathrm{D}$ & $\mathrm{A}$ & & $\mathrm{A}$ & & \begin{tabular}{c|c}
$C$ \\
\end{tabular} & $\begin{array}{cc}C \\
C\end{array}$ & $C_{n}$ & $B$ & \\
\hline $\mathrm{D}$ & $\begin{array}{ll} \\
\end{array}$ & $\mathrm{A}$ & $\mathrm{A}_{\mathrm{A}}$ & \begin{tabular}{c|c} 
& 5
\end{tabular} & 5 & \begin{tabular}{l|l}
3 & $\mathrm{~A}$ \\
\end{tabular} & & $B$ & $\begin{array}{ll} \\
\end{array}$ & $\mathrm{D}$ & $\mathrm{A}$ & \begin{tabular}{l|l}
$B$ & $A$
\end{tabular} & $A B$ & \begin{tabular}{|l|l}
$A$ \\
\end{tabular} & & \\
\hline
\end{tabular}

(c)

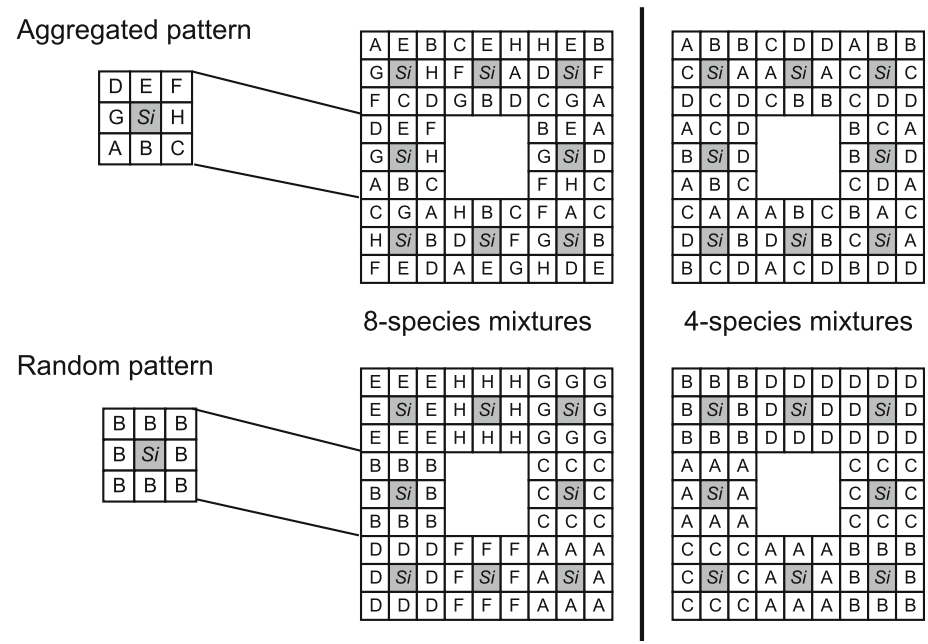

\section{Statistical analyses}

A hierarchical generalized linear mixed effects model (lme function from the nlme library of $\mathrm{R}$ ), with spatial pattern and mixture type as fixed effects and plot as a random factor, was used to test for differences in total resident standing biomass and percentages of grasses, forbs and legumes. Mixture type, spatial pattern and their interactions were tested at the plot-level using block:plot as error term. Resident standing biomasses at first and second harvest were log-transformed to reduce heteroscedasticity and the models were fitted with a Gaussian error distribution. Models fitted with a binomial error distribution were used to analyze differences in percentage of grasses, legumes, and forbs between plot level treatments.

For analyzing target plants, we used hierarchical generalized linear mixed effects models (glmmPQL function from the MASS library of R) with mixture type, spatial pattern and genotype's range (hereafter called "range effect") as fixed effects and sub-subplot nested into subplot nested 
into plot nested into block as random factors. Target species were analyzed separately since the difference in invasion mechanisms might affect the response of target plants. Mixture type, spatial pattern, and their interaction were tested at the plot-level using block:plot as error term. The range effect was tested at the subplot level using the lowestlevel error term. When the interactions were significant, we used the likelihood-ratio test to select for the best or minimal model. Binary data (i.e., survival, survival after resprouting, and flowering) were analyxed by fitting a generalized linear mixed model with a binomial error distribution. Count data (capitulum production) were analyzed by fitting a generalized linear mixed model with a Poisson error distribution. Since residual deviance was larger then residual degrees of freedom, revealing overdispersion, the models were re-fitted with quasi-binomial and quasi-Poisson distributions (Crawley 2005). Since $C$. stoebe did not flower during the experiment, reproductive output (flowering probability and capitulum production) was analyzed for $S$. inaequidens only and at the first harvest only because very few targets flowered after resprouting. Biomass at the subsubplot level (mean of 8 individuals) was log-transformed to reduce heteroscedasticity and analyzed by fitting a Gaussian error distribution to the linear mixed model. All the analyses were carried out with R 2.10.1 (R Development Core Team 2009). Significance level was considered when $P<0.10$ for model simplification and when $P<0.05$ in all other cases.

\section{Results}

Resident biomass

Resident total standing biomass of plots was not significantly different between the first $\left(308.4 \pm 25.9 \mathrm{~g} \mathrm{~m}^{-2}\right)$ and the second harvest $\left(371.5 \pm 27.7 \mathrm{~g} \mathrm{~m}^{-2}\right)$. Irrespective of harvest time, there were no significant differences between assemblages in total standing biomass and the proportion of grasses and legumes, indicating no effect of mixture type and spatial pattern on plant productivity.

Target species' performances

For both target species, survival after 15 days was high (mean survival ranging from 97.5 to $100 \%$ ), revealing no significant mortality due to the experimental setup.

\section{Centaurea stoebe's performances}

Centaurea stoebe's mean survival at the first harvest ranged from 59.4 to $79.8 \%$ depending on community spatial pattern and genotype's range. Early survival of native and introduced genotypes of $C$. stoebe was not affected by spatial pattern (Table 1; Fig. 2a). Mean survival after resprouting only ranged from 3.6 to $31.5 \%$ (Fig. $2 b$ ). After resprouting, survival of both native and introduced genotypes was higher in intra-specifically aggregated mixtures than in randomly assembled ones (Table 1; Fig. 2b).

After 1.5 months, biomass of native genotypes of $C$. stoebe was significantly affected by spatial pattern (Table 1) and was higher in intra-specifically aggregated mixtures than randomly assembled ones (Fig. 3a). By contrast, spatial pattern had no effect on introduced genotypes' biomass (Fig. 3a). After 4 months, spatial pattern and genotype's range had no effect on the biomass of resprouted targets (Table 1). None of C. stoebe did flower during the experiment.

\section{Senecio inaequidens' performances}

Mean target survival ranged from 61.6 to $87.5 \%$ and from 11.9 to $41.9 \%$ after 1.5 months and after resprouting, respectively. Survival of $S$. inaequidens was not significantly affected by spatial pattern and genotype's range (Table 1).

Early growth of both genotypes of $S$. inaequidens was affected marginally significantly by spatial pattern (Table 1 ; Fig. 3b). Biomass of both genotypes was higher in intraspecifically aggregated mixtures than in randomly assembled ones (Fig. 3b). In addition, biomass of genotypes from the introduced range of $S$. inaequidens was consistently and marginally higher than biomass of genotypes from the native range (Table 1; Fig. 3b). After 4 months, spatial pattern and genotype's range had no effect on the biomass of resprouted targets (Table 1).

Senecio inaequidens' flowering was not affected by spatial pattern. There was no difference between genotype's range (Table 2). The effect of spatial pattern on capitulum production was mixture-dependent, as shown by the significant interaction term between spatial pattern and mixture type (Table 2). In 4-species mixtures, capitulum production was higher in intra-specifically aggregated than in randomly assembled mixtures ones, whereas in 8-species mixtures, capitulum production of $S$. inaequidens was lower intra-specifically aggregated than in randomly assembled mixtures ones (Fig. 4). Overall, introduced genotypes produced significantly more capitula than native ones (Table 2 ; Fig. 4).

\section{Discussion}

In this experiment, we tested whether (1) establishment success of exotic species was affected by the spatial arrangement of the resident species in the receiving community 
Table 1 Centaurea stoebe's and Senecio inaequidens' survival and biomass after 1.5 months and after 4 months

\begin{tabular}{|c|c|c|c|c|c|c|c|c|c|c|c|c|}
\hline & \multicolumn{6}{|c|}{ Survival $^{\mathrm{a}}$} & \multicolumn{6}{|c|}{ Biomass $^{b}$} \\
\hline & \multicolumn{3}{|c|}{ 1.5 Months } & \multicolumn{3}{|c|}{4 Months (resprouted plants) } & \multicolumn{3}{|c|}{ 1.5 Months } & \multicolumn{3}{|c|}{4 Months (resprouted plants) } \\
\hline & $d f$ & $F$ value & $P$ value & $d f$ & $F$ value & $P$ value & $d f$ & $F$ value & $P$ value & $d f$ & $F$ value & $P$ value \\
\hline \multicolumn{13}{|l|}{ Centaurea stoebe } \\
\hline \multicolumn{13}{|l|}{ Plot level } \\
\hline Mixture & 1 & 0.022 & 0.885 & 1 & 0.305 & 0.593 & 1 & 3.445 & 0.093 & 1 & 0.012 & 0.916 \\
\hline Spatial pattern & 1 & 0.437 & 0.524 & 1 & 5.887 & 0.036 & 1 & 1.938 & 0.194 & 1 & 2.560 & 0.171 \\
\hline Residuals & 10 & & & 10 & & & 10 & & & 5 & & \\
\hline \multicolumn{13}{|l|}{ Sub-subplot level } \\
\hline Range & 1 & 0.473 & 0.503 & 1 & 0.135 & 0.719 & 1 & 1.966 & 0.184 & 1 & 2.397 & 0.197 \\
\hline Mixture $\times$ range & 1 & 6.164 & 0.026 & & & & 1 & 10.847 & 0.006 & & & \\
\hline Spatial pattern $\times$ range & & & & & & & 1 & 4.531 & 0.053 & & & \\
\hline Residuals & 14 & & & 15 & & & 13 & & & 4 & & \\
\hline \multicolumn{13}{|l|}{ Senecio inaequidens } \\
\hline \multicolumn{13}{|l|}{ Plot level } \\
\hline Mixture & 1 & 1.709 & 0.220 & 1 & 0.296 & 0.598 & 1 & 6.335 & 0.031 & 1 & 1.492 & 0.250 \\
\hline Spatial pattern & 1 & 2.386 & 0.154 & 1 & 0.523 & 0.486 & 1 & 3.542 & 0.093 & 1 & 0.690 & 0.425 \\
\hline Residuals & 10 & & & 10 & & & 10 & & & 10 & & \\
\hline \multicolumn{13}{|l|}{ Sub-subplot level } \\
\hline Range & 1 & 0.242 & 0.630 & 1 & 0.278 & 0.606 & 1 & 4.187 & 0.059 & 1 & 0.058 & 0.815 \\
\hline Mixture $\times$ range & & & & 1 & 10.637 & 0.006 & & & & & & \\
\hline \multicolumn{13}{|l|}{ Spatial pattern $\times$ range } \\
\hline Residuals & 15 & & & 14 & & & 15 & & & 9 & & \\
\hline
\end{tabular}

Results of hierarchical generalized linear mixed effects ( ${ }^{\mathrm{a}}$ fitted with a quasibinomial error distribution) and hierarchical linear mixed effects ( ${ }^{\mathrm{b}}$ fitted with a Gaussian error distribution) models testing effects of mixture type (4-species vs. 8-species mixture), spatial pattern (random vs. aggregated), genotype's range (native vs. introduced) and their interactions. Non-significant interactions have been removed on the basis of likelihood-ratio tests Residual degrees of freedom differ because insignificant interactions have been omitted

Fig. 2 Survival of genotypes from the native and introduced ranges of $C$. stoebe $\mathbf{a} 1.5$ months after planting and $\mathbf{b}$ after resprouting (survival after 4 months), in response to spatial pattern (Rand random or Aggr aggregated) in the two mixture types (Mix 4 4-species and Mix 88 -species mixtures) of experimentally assembled resident communities. Values are mean $+\mathrm{SE}$
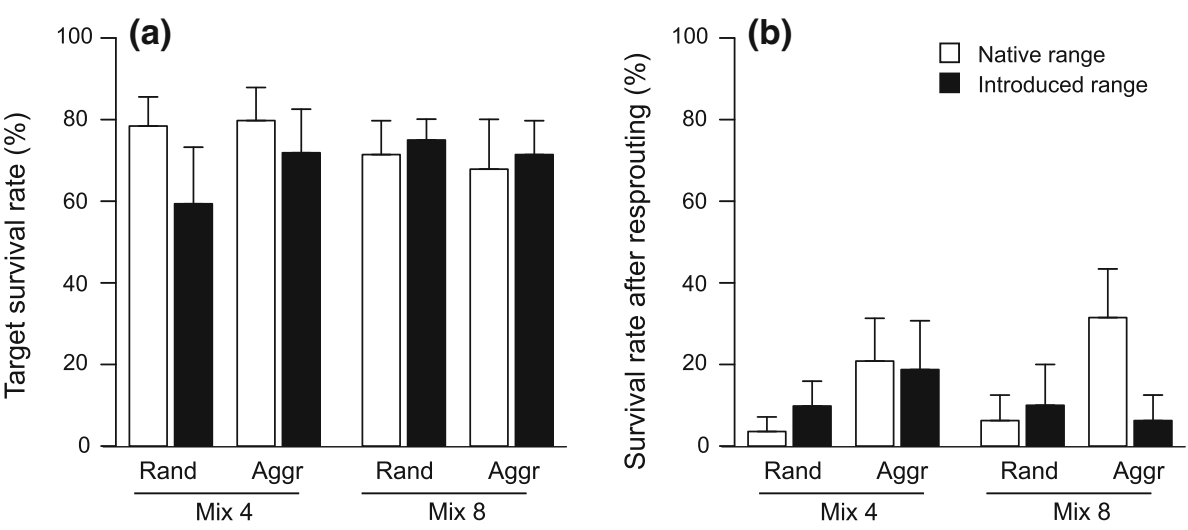

and whether this effect depends on (2) community composition and/or (3) exotic species' characteristics.

Intra-specific aggregation promotes invasibility

As expected, intra-specifically aggregated resident species decreased community resistance to establishment of exotic species compared to randomly assembled ones. Early growth of both exotic species was greater in spatially aggregated mixtures than in randomly assembled ones. In addition, survival after resprouting of $C$. stoebe was higher in intra-specifically aggregated mixtures than in randomly assembled ones. Since resource use and complementarity decrease with intra-specific aggregation (De Boeck et al. 2006; Mokany et al. 2008), a higher availability of resources in aggregated communities may enhance growth of newly establishing plants. Considering invasibility of the community as the lack of resistance to the arrival of a new 

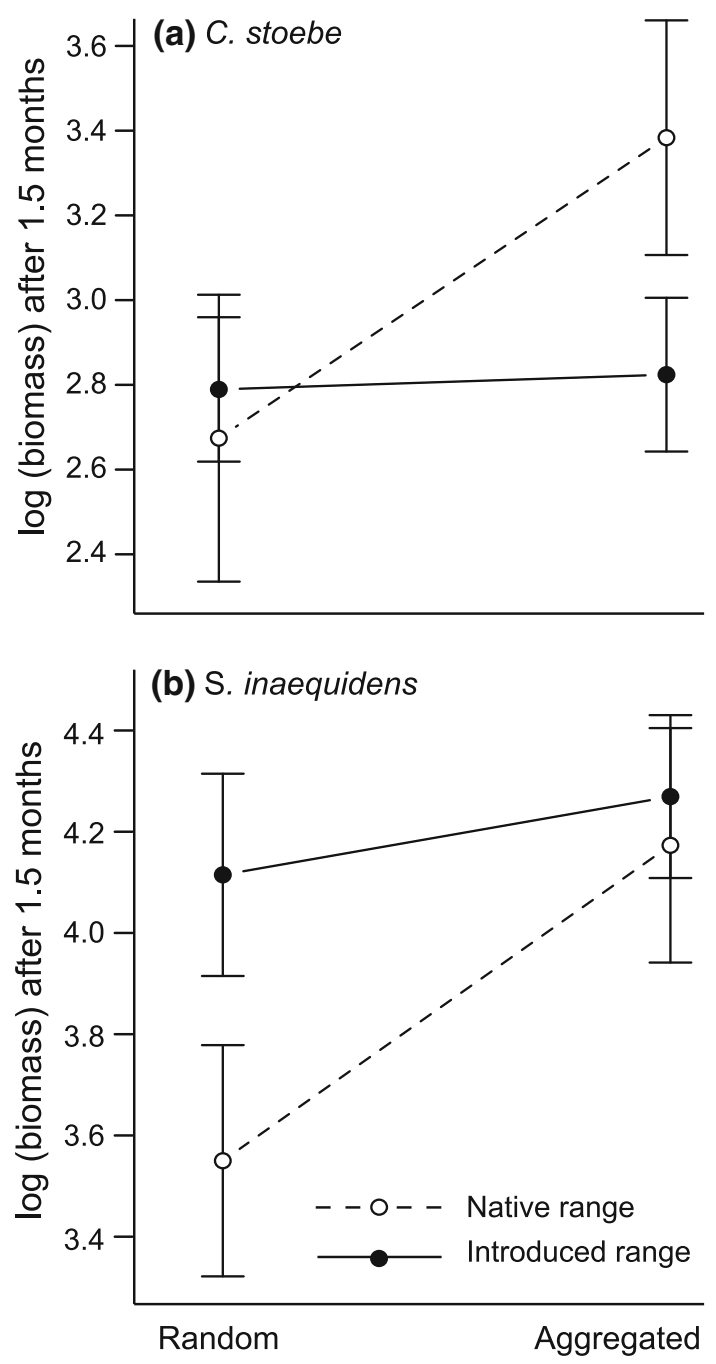

Fig. 3 Standing biomass of genotypes from native and introduced ranges after 1.5 months of $\mathbf{a} C$. stoebe and $\mathbf{b} S$. inaequidens in response to spatial pattern of experimentally assembled resident communities. Values are mean $\pm \mathrm{SE}$

individual, regardless of the invasive potential of this new species, invasibility could be promoted by community intra-specific aggregation. This is in agreement with the notion that intra-specific aggregation promotes species coexistence within the community by limiting competitive effects of the most dominant species (Stoll and Prati 2001; Monzeglio and Stoll 2005; De Boeck et al. 2006; Mokany et al. 2008; Lamosova et al. 2010).

Species-dependent interaction between invasiveness and invasibility

Genotypes from native and introduced ranges of the invasive species were differently affected by spatial pattern. This range-dependent response might be linked to phenotypic plasticity, which is the property of a genotype to express different phenotypes in different environments (Bradshaw 1965). Because plasticity may allow organisms to cope with a broader range of environments, it has been suggested to explain invasiveness (Richards et al. 2006), since it could enhance niche breadth (Bradshaw 1965; Richards et al. 2008). Richards et al. (2006) argued that invaders may benefit from plasticity through three strategies. According to the Jack-of-all-trades strategy, the invader is able to maintain fitness in unfavorable environments, by contrast to the opportunistic Master-of-some strategy, which states that the invader is able to increase its fitness in favorable environments. Since these two strategies are not mutually exclusive, the Jack-and-Master strategy is a combination of the former ones, where the invader does well in all kinds of environments and is also able to take advantage of favorable conditions (Richards et al. 2006).

The effect of spatial pattern on early establishment of C. stoebe was range-dependent. Genotypes from the native range had higher biomass in intra-specifically aggregated mixtures as compared to randomly assembled ones, whereas biomass of genotypes from the introduced range was similar in randomly assembled and intra-specifically aggregated mixtures. Consequently, genotypes from the introduced range of $C$. stoebe were better able to cope with competitive environments, such as spatially randomly assembled mixtures, than native ones. This is characteristic of a Jack-of-alltrades strategy, as genotypes from the introduced range were not affected by community spatial pattern and were able to perform equally well in all conditions. By contrast, native genotypes behaved as a Master-of-some strategist, being able to increase performance in changing environments. Spatial pattern affected both genotypes of $S$. inaequidens in the same way, revealing no interaction between invasiveness and invasibility. Since genotypes from the introduced range always had higher growth than the ones from the native range, they can therefore be defined as Jack-and-Master strategists, while the genotypes from the native range can be defined as Master-of-some strategists.

Native genotypes of both target species behaved as Master-of-some strategist, showing the ability to increase their performances according to the changes in the recipient community. By contrast, the strategies of the genotypes from the introduced range were species-dependent. On the one hand, the establishment success of $C$. stoebe in the introduced range could be due to the ability of North American genotypes to deal with all kinds of environments, by contrast to European ones. On the other hand, S. inaequidens' establishment success may be explained by a high ability of genotypes from the introduced range to cope with all kinds of environments, as well as to take advantage of favorable environments, such as spatially aggregated communities. 
Table 2 S. inaequidens's flowering and capitulum production during the first 1.5 months

\begin{tabular}{|c|c|c|c|c|c|c|}
\hline & \multicolumn{3}{|c|}{ Flowering $^{\mathrm{a}}$} & \multicolumn{3}{|c|}{ Capitulum production $^{\mathrm{b}}$} \\
\hline & $d f$ & $F$ value & $P$ value & $d f$ & $F$ value & $P$ value \\
\hline \multicolumn{7}{|l|}{ Plot level } \\
\hline Mixture & 1 & 6.304 & 0.031 & 1 & 4.672 & 0.083 \\
\hline Spatial pattern & 1 & 0.736 & 0.411 & 1 & 4.485 & 0.088 \\
\hline Mixture: spatial pattern & & & & 1 & 27.442 & 0.003 \\
\hline Residuals & 10 & & & 5 & & \\
\hline \multicolumn{7}{|l|}{ Sub-subplot level } \\
\hline Range & 1 & 2.461 & 0.138 & 1 & 33.277 & 0.005 \\
\hline Residuals & 15 & & & 4 & & \\
\hline
\end{tabular}

Results of hierarchical generalized linear mixed effects models respectively fitted with a ${ }^{\mathrm{a}}$ quasibinomial or ${ }^{\mathrm{b}}$ quasipoisson error distribution to test effects of mixture type, spatial, genotype's range and their interactions. See Table 1 for more details

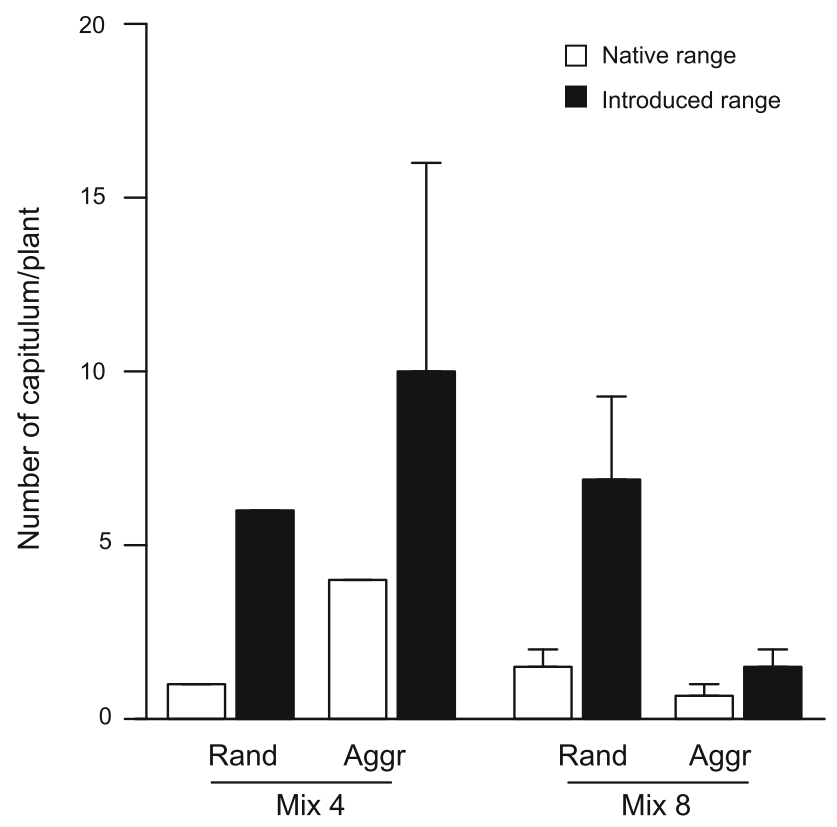

Fig. 4 Capitulum production of genotypes from native and introduced ranges of $S$. inaequidens after 1.5 months, in response to spatial pattern in the two mixture types. Capitulum production is the number of capitula produced by flowering plant. Values are means $+\mathrm{SE}$

The effect of spatial pattern on establishment success are modulated by community type

Spatial heterogeneity, by limiting intra-specific competition, has been hypothesized to drive the positive relationship between invasibility and diversity (Davies et al. 2005). The effect of spatial pattern on $S$. inaequidens' reproductive output was different according to the mixture type. While intra-specific aggregation of resident species promoted capitulum production of $S$. inaequidens in 4-species mixtures, it limited it in 8-species mixtures. Since capitulum production, through propagule pressure, may be the key trait responsible for invasive success of some exotic species (Lockwood et al. 2005) and of S. inaequidens in particular (Thébault et al. 2011), interactive effects of spatial pattern and community type may play a central role in community invasibility, and this deserves more studies. The two mixture types used in this experiment were not different in terms of productivity, but differed in terms of number of species, functional groups, and identity of resident species. This mixture dependency of spatial pattern effect on $S$. inaequidens' capitulum production, as well as the mixture type effect on early biomass of both $S$. inaequidens and $C$. sto$e b e$, could be the result of a selection effect since some of the additional species in the 8 -species mixtures could be facilitating species for growth of $S$. inaequidens or $C$. steobe (Palmer and Maurer 1997; Levine and D'Antonio 1999). Only an experiment with all the combinations of 4-species and 8-species mixtures using these 8 species could have addressed this question, which was beyond the scope of this study.

As highlighted by our results, working with genotypes from the introduced and native ranges of a given invasive species allows the study of the interaction between invasiveness and invasibility, which provides key insights to understand invasive success. In addition, for the first time, we assessed the effect of intra-specific spatial aggregation of resident species on community resistance to invasion. We highlighted the importance of studying the effects of spatial pattern in different plant communities, since spatial pattern and community composition, both thought to control invasibility, may interact on community resistance. Consequently, interactive effects of spatial patterns with community composition or diversity deserve more studies. We acknowledge that these results may change if our experiment had been run for a longer time. However, the resident species would have spread within the microcosm and the spatial structure would have changed, complicating our understanding of the pattern (Lamosova et al. 2010). 
Despite the short duration of the experiment, all resident species reached their full size and some of them even flowered.

We acknowledge that two species are not enough to draw strong conclusions and that this experiment has to be considered as a starting point for the study of the effects of spatial patterns on invasive success. Despite species-specific responses, the two model species used in this experiment were affected by community spatial pattern. We expect that the effects of spatial pattern on invasive success will probably be confirmed in later studies, which will have important implications in terms of management, since lower evenness, higher number of species with clonal growth, or limited seed dispersal might increase intraspecific aggregation within communities and therefore invasibility.

Acknowledgments This project was funded by the National Centre of Competence in Research (NCCR) Plant Survival, a research program of the Swiss National Science Foundation. We thank Richard Bardgett for useful comments in editing and Pilar Gomis Bataller and Elena Rossel for technical assistance. We are grateful to Olivier Broennimann, Signe Normand and Urs Treier for collecting seeds of Centaurea stoebe, and to Daniel Prati for supplying seeds of Senecio inaequidens. This experiment complied with the Swiss regulation for invasive plant experimentations, as stated by the Federal Office for the Environment (FOEN).

\section{References}

Bazzaz FA (1986) Life history of colonizing plants: some demographic, genetic, and physiological features. In: Mooney HA, Drake JA (eds) Ecology of biological invasions of North America and Hawaii. Springer, Berlin, pp 96-110

Bornkamm R (2002) On the phytosociological affiliations of an invasive species Senecio inaequidens in Berlin. Preslia Praha 74:395-407

Bradshaw AD (1965) Evolutionary significance of phenotypic plasticity in plants. Adv Genet 13:115-155

Broennimann O, Treier UA, Muller-Scharer H, Thuiller W, Peterson AT, Guisan A (2007) Evidence of climatic niche shift during biological invasion. Ecol Lett 10:701-709

Callaway RM, Aschehoug ET (2000) Invasive plants versus their new and old neighbors: a mechanism for exotic invasion. Science 290:521-523

Catford JA, Jansson R, Nilsson C (2009) Reducing redundancy in invasion ecology by integrating hypotheses into a single theoretical framework. Divers Distrib 15:22-40. doi:10.1111/j.14724642.2008.00521.x

Crawley MJ (2005) Statistics: an introduction using R. Wiley, West Sussex

Damgaard C (2010) Intraspecific aggregation does not increase species richness in dune grasslands. J Ecol 98:1141-1146. doi:10.1111/ j.1365-2745.2010.01692.x

Davies KF, Chesson P, Harrison S, Inouye BD, Melbourne BA, Rice KJ (2005) Spatial heterogeneity explains the scale dependence of the native-exotic diversity relationship. Ecology 86:1602-1610

De Boeck HJ, Nijs I, Lemmens C, Ceulemans R (2006) Underlying effects of spatial aggregation (clumping) in relationships between plant diversity and resource uptake. Oikos 113:269-278
Dlugosch KM, Parker IM (2008) Founding events in species invasions: genetic variation, adaptive evolution, and the role of multiple introductions. Mol Ecol 17:431-449

Duncan C (2001) Knapweed management: another decade of changes. In: Smith L (ed) Proceedings of the First International Knapweed Symposium of the 21st Century. United States Department of Agriculture, Agricultural Research Service, Albany, CA, US, Coeur d'Alene, Idaho, pp 1-7

Ehrenfeld JG (2003) Effects of exotic plant invasions on soil nutrient cycling processes. Ecosystems 6:503-523. doi:10.1007/s10021002-0151-3

Eppinga MB, Rietkerk M, Dekker SC, De Ruiter PC, Van der Putten WH (2006) Accumulation of local pathogens: a new hypothesis to explain exotic plant invasions. Oikos 114:168-176

Ernst WHO (1998) Invasion, dispersal and ecology of the South African neophyte Senecio inaequidens in The Netherlands: from wool alien to railway and road alien. Acta Botanica Neerlandica 47: 131-151

Gordon DR (1998) Effects of invasive, non-indigenous plant species on ecosystem processes: lessons from Florida. Ecol Appl 8:975989. doi:10.1890/1051-0761(1998)008[0975:eoinip]2.0.co;2

Hierro JL, Maron JL, Callaway RM (2005) A biogeographical approach to plant invasions: the importance of studying exotics in their introduced and native range. J Ecol 93:5-15

Hook PB, Olson BE, Wraith JM (2004) Effects of the invasive forb Centaurea maculosa on grassland carbon and nitrogen pools in Montana, USA. Ecosystems 7:686-694

Keane RM, Crawley MJ (2002) Exotic plant invasions and the enemy release hypothesis. Trends Ecol Evol 17:164-170

Lafuma L, Balkwill K, Imbert E, Verlaque R, Maurice S (2003) Ploidy level and origin of the European invasive weed Senecio inaequidens (Asteraceae). Plant Syst Evol 243:59-72

Lamosova T, Dolezal J, Lanta V, Leps J (2010) Spatial pattern affects diversity-productivity relationships in experimental meadow communities. Acta Oecol 36:325-332. doi:10.1016/j.actao. 2010.02.005

Levine JM, D'Antonio CM (1999) Elton revisited: a review of evidence linking diversity and invasibility. Oikos 87:15-26

Levine JM, Vila M, D'Antonio CM, Dukes JS, Grigulis K, Lavorel S (2003) Mechanisms underlying the impacts of exotic plant invasions. Proc R Soc Lond B 270:775-781

Lockwood JL, Cassey P, Blackburn T (2005) The role of propagule pressure in explaining species invasions. Trends Ecol Evol 20:223-228

Mack RN, Simberloff D, Lonsdale WM, Evans H, Clout M, Bazzaz FA (2000) Biotic invasions: causes, epidemiology, global consequences, and control. Ecol Appl 10:689-710

Mack MC, D'Antonio CM, Ley RE (2001) Alteration of ecosystem nitrogen dynamics by exotic plants: a case study of C-4 grasses in Hawaii. Ecol Appl 11:1323-1335. doi:10.1890/1051-0761(2001) 011[1323:aoendb]2.0.co;2

Maron JL, Vila M (2001) When do herbivores affect plant invasion? Evidence for the natural enemies and biotic resistance hypotheses. Oikos 95:361-373

Mokany K, Ash J, Roxburgh S (2008) Effects of spatial aggregation on competition, complementarity and resource use. Austral Ecol 33:261-270. doi:10.1111/j.1442-9993.2007.01813.x

Monzeglio U, Stoll P (2005) Spatial patterns and species performances in experimental plant communities. Oecologia 145:619-628. doi:10.1007/s00442-005-0168-3

Palmer MW, Maurer TA (1997) Does diversity beget diversity? A case study of crops and weeds. J Veg Sci 8:235-240

Pimentel D, Lach L, Zuniga R, Morrison D (2000) Environmental and economic costs of nonindigenous species in the United States. Bioscience 50:53-65 
Prieur-Richard AH, Lavorel S (2000) Invasions: the perspective of diverse plant communities. Austral Ecol 25:1-7

R Development Core Team (2009) R: a language and environment for statistical computing. R Foundation for Statistical Computing, Vienna, Austria. ISBN 3-900051- 07-0. http://www.R-project.org

Reinhart KO, Gurnee J, Tirado R, Callaway RM (2006) Invasion through quantitative effects: intense shade drives native decline and invasive success. Ecol Appl 16:1821-1831

Richards CL, Bossdorf O, Muth NZ, Gurevitch J, Pigliucci M (2006) Jack of all trades, master of some? On the role of phenotypic plasticity in plant invasions. Ecol Lett 9:981-993

Richards CL, Walls RL, Bailey JP, Parameswaran R, George T, Pigliucci M (2008) Plasticity in salt tolerance traits allows for invasion of novel habitat by Japanese knotweed s. 1. (Fallopia japonica and F-bohemica, Polygonaceae). Am J Bot 95:931-942. doi:10.3732/ajb.2007364

Shea K, Chesson P (2002) Community ecology theory as a framework for biological invasions. Trends Ecol Evol 17:170-176

Simberloff D (2009) The role of propagule pressure in biological invasions. Annu Rev Ecol Evol Syst 40:81-102

Skinner K, Smith L, Rice P (2000) Using noxious weed lists to prioritize targets for developing weed management strategies. Weed Sci 48:640-644
Stoll P, Prati D (2001) Intraspecific aggregation alters competitive interactions in experimental plant communities. Ecology 82:319327

Thébault A, Frey B, Mitchell EAD, Buttler A (2010) Species-specific effects of polyploidisation and plant traits of Centaurea maculosa and Senecio inaequidens on rhizosphere microorganisms. Oecologia 163:1011-1020. doi:10.1007/s00442-010-1598-0

Thébault A, Gillet F, Müller Schärer H, Buttler A (2011) Polyploidy and invasion success: trait trade-offs in native and introduced cytotypes of two Asteraceae species. Plant Ecol 212(315):325

Treier UA, Broennimann O, Normand S, Guisan A, Schaffner U, Steinger T, Müller-Schärer H (2009) Shift in cytotype frequency and niche space in the invasive plant Centaurea maculosa. Ecology 90:1366-1377

Vitousek PM, D'Antonio CM, Loope LL, Rejmanek M, Westbrooks R (1997) Introduced species: a significant component of humancaused global change. N Z J Ecol 21:1-16

Walker LR, Vitousek PM (1991) An invader alters germination and growth of a native dominant tree in Hawaii. Ecology 72:1449 1455

Watson AK, Renney AJ (1974) The biology of Canadian weeds: Centaurea diffusa and Centaurea maculosa. Can J Plant Sci 54: 687-701 